\title{
Design and Construction of an Underground TEM Lab at Brigham Young University
}

\author{
J. K. Farrer, R. R. Vanfleet, R. C. Davis, F. C. Anderson and T. W. Leishman \\ Department of Physics and Astronomy, Brigham Young University, N283 ESC, Provo UT 84602
}

The environment in which a TEM is installed is critical to the performance of the instrument. Among many concerns is the interference that can be caused by existing mechanical or acoustical vibrations, electro-magnetic interference (EMI) and thermal fluctuations[1]. Studies have shown various techniques that can be employed to reduce or eliminate the external interference[2]. In 2003 Brigham Young University completed the construction of a TEM facility. The installation of the microscopes (FEI, models Tecnai F30 \& Tecnai F20 EFTEM) was completed in July of 2004. The facility was designed to meet or exceed the specifications from the microscope and other equipment manufacturers. This work will report on the design and construction of the facility and include a discussion of the measured effectiveness of both the well-known and the not-so-well-known procedures for eliminating the ambient disturbances.

Prior to the initial design, the specifications from the equipment manufacturers were reviewed. The methods for measuring mechanical vibrations differ for different manufacturers. As an example, FEI Company takes RMS, third-octave acceleration measurements of the vibration over a particular bandwidth for three perpendicular axes; two parallel (X and $Y$ ) and one perpendicular $(\mathrm{Z})$ to the floor. The threshold of vibration acceleration for the $\mathrm{X}$ axis is shown in figure 1 by the dotted line. For acoustical vibrations the ambient noise must be less than $70 \mathrm{~dB}$ for the entire spectrum and less than $55 \mathrm{~dB}$ per individual third-octave band between 10 and $10000 \mathrm{~Hz}$, indicated by the dotted line in figure 2[3]. EMI requirements, given by Gatan Inc. for their GIF Tridiem ER (865), specified that the line frequency must be less than $1 \mathrm{mG}$ with all other frequencies less than $0.1 \mathrm{mG}[4]$. The thermal fluctuations of the GIF were loosely required to be less than $\pm 0.1^{\circ} \mathrm{C}$ per $1 \mathrm{hr}$.

A few of the design elements used to reduce ambient interference are summarized here. The TEM rooms were built on a separate foundation and a physical gap, with no rigid connections, was maintained between the walls separating the TEM rooms from the main building. This was done to insulate the TEM rooms from vibrations generated in the main building. Custom magnetic field shielding was installed in both rooms to reduce any existing and future increases in AC magnetic field levels. The walls were then paneled with standard acoustic absorptions panels with coated fabric for particulate reduction. The instruments physically sit on a concrete block that is $3 \mathrm{ft}$ thick and physically isolated from the floor of the microscope room. Water-cooled ceiling tiles were installed to minimize the amount of forced air needed to maintain thermal stability of the room. Greater details of all the design components are to be presented.

Measurements of the ambient conditions of the TEM rooms have been taken at various stages of the construction as well as after completion and installation. All of the data reported here, except the temperature measurements, were acquired from one of the microscope rooms after installation of the instrument, but before the instrument was powered on. The temperature measurements were performed with the instrument fully operational. Mechanical vibrations measured in the X direction are plotted in figure 1. The highest third-octave band was around $40 \mathrm{~Hz}$ with the RMS acceleration 
was recorded at $0.04 \mathrm{mg}$. Figure 2 shows the RMS third-octave acoustical levels for $10 \mathrm{~Hz}$ to $1 \mathrm{kHz}$. The highest value is around $60 \mathrm{~Hz}$, but is well below the threshold of $55 \mathrm{~dB}$. Figure 3 shows the peak to peak EMI measured at the column in the X direction. The peaks at $60 \mathrm{~Hz}$ and $180 \mathrm{~Hz}$ are 0.02 and $0.01 \mathrm{mGauss}$ respectively. The temperature measurements in the room also indicated fluctuations below the required threshold. However, temperature fluctuations on the surface of the GIF unit were found to exceed the specifications set by Gatan Inc. These fluctuations are caused by the chilled water that is supplied directly to the GIF unit, not the heating-cooling system installed in the room. Table 1 is a summary of all the results for this particular set of measurements.

[1] R.H. Alderson, Practical Methods in Electron Microscopy, vol. 4 New York: Elsevier, 1975. [2] J. Murphy, in Procedures in Electron Microscopy, John Wiley \& Sons: Toronto, 1993. [3] FEI, Preinstallation Instruction Manual; Tecnai G2 20, FEI Company: Eindhoven,1998. [4] B. Pelczar, Site Survey Report, Vibration Engineering Consultants: Santa Cruz, 2004.

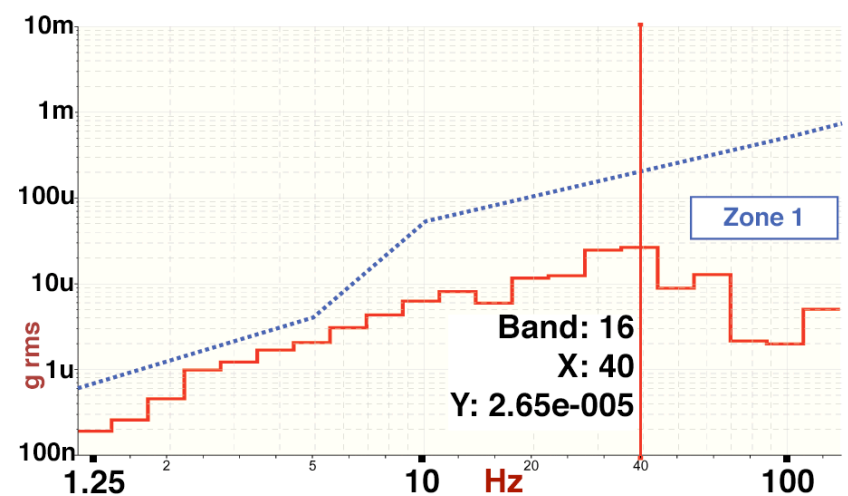

Figure 1. RMS acceleration of mechanical vibrations measured in the $\mathrm{X}$ direction. Manufacturer's specification shown by dotted line.

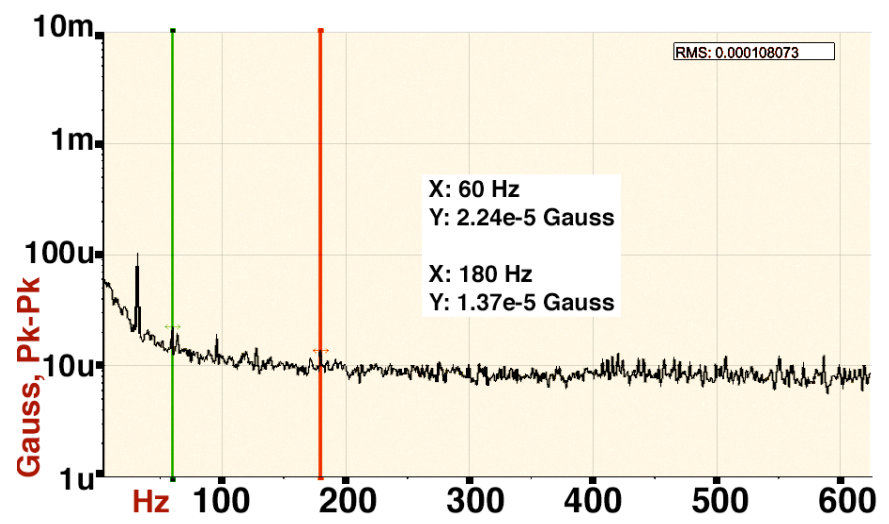

Figure 3. Peak to Peak EMI measured at the column in the $\mathrm{X}$ direction. Peaks at 60 and $180 \mathrm{~Hz}$ are marked with green and red lines respectively. The peak at $32 \mathrm{~Hz}$ is an artifact of the measurement and is not an EMI peak.

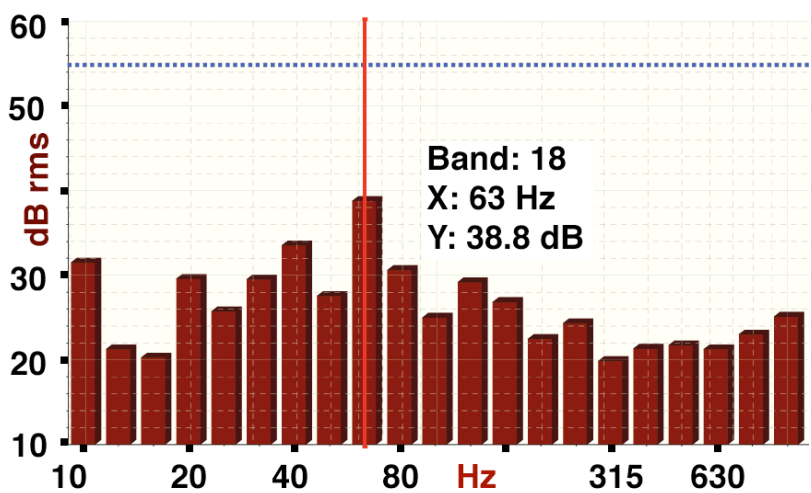

Figure 2. RMS third-octave measurements of acoustical vibrations. Manufacturer's specification shown by dotted line.

Table 1. Summary of results

\begin{tabular}{|c|c|c|c|}
\hline \multicolumn{4}{|c|}{ Vibration Levels } \\
\hline \multirow{2}{*}{ Direction } & \multicolumn{3}{|c|}{ Largest Acceleration Band } \\
\hline & mg RMS & Band & $\mathrm{Hz}$ \\
\hline X-Front-Back & 0.04 & 16 & 40 \\
\hline Y-Left-Right & 0.04 & 16 & 40 \\
\hline Z-Up-Down & 0.03 & 13 & 20 \\
\hline \multicolumn{4}{|c|}{ EMI - at the column } \\
\hline & $\begin{array}{c}60 \mathrm{~Hz} \\
\mathrm{P} \text { to } \mathrm{P} \\
\text { mGauss }\end{array}$ & $\begin{array}{c}180 \mathrm{~Hz} \\
\mathrm{P} \text { to } \mathrm{P} \\
\text { mGauss }\end{array}$ & $\begin{array}{c}\text { Total } \\
\text { Spectra } \\
\text { RMS } \\
\end{array}$ \\
\hline $\mathrm{X}$ & 0.02 & 0.01 & 0.11 \\
\hline Y & 0.02 & 0.01 & 0.11 \\
\hline $\mathrm{Z}$ & 0.02 & 0.01 & 0.11 \\
\hline \multicolumn{4}{|c|}{ DC Field Change, mGauss $\mathrm{P}$ to $\mathrm{P}-$ at the column } \\
\hline $\mathrm{X}$ & \multicolumn{3}{|c|}{$\Delta 0.017$} \\
\hline $\mathrm{Y}$ & \multicolumn{3}{|c|}{$\Delta 0.019$} \\
\hline Z & \multicolumn{3}{|c|}{$\Delta 0.019$} \\
\hline \multicolumn{4}{|c|}{ Acoustics - RMS } \\
\hline Largest & $38.8 \mathrm{~dB}$ & Band 18 & $63 \mathrm{~Hz}$ \\
\hline
\end{tabular}

